\title{
MONITORING OF CAVES
}

\section{Conclusions and Recommendations}

In order to reduce the human impact on cave environment, a show cave must be monitored. The most relevant parameters to be monitored are:

- Air temperature $\left({ }^{\circ} \mathrm{C}\right)$

- Water temperature $\left({ }^{\circ} \mathrm{C}\right)$ (if applicable)

- Relative humidity (\%)

- $\mathrm{CO}_{2}$ concentration $(\mathrm{ppm})$

- Radon concentration $\left(\mathrm{Bq} / \mathrm{m}^{3}\right)$

A frequency of four measurements per day (e.g., at 6:00, 12:00, 18:00 and 24:00) is suitable in most cases. A preliminary monitoring network should be operated at least for one year, and possibly for two, if it has to be replaced by an automatic monitoring network.

\section{Introduction}

Cave environment is often rather easily influenced by natural and anthropic factors. In general the effects of natural factors cannot be avoided and therefore they result in the normal evolution of a cave. Anthropic effects, on the other hand, must be kept as small as reasonably achievable, economic and social factors having been taken into account.

The UIS (Union Internationale de Spéléologie) Commission for protection, exploration and tourism of caves and karst regions, during the $13^{\text {th }}$ Int. Congress of Speleology held in Brazil in July 2001, approved a report as a guideline for the time being. In particular show caves managers were requested to put the greatest care in the management of their caves since these belong to the patrimony of the whole world.

Anyway the process of optimising the protection of a cave environment should be extended to the whole area where a cave opens. The procedure of optimisation should also be applied when an existing situation is being reviewed.

In order to develop such a process it is necessary to know a number of parameters characterising the environment under consideration. In the next paragraphs a description of the different aspects of data collection is reported.

It must be emphasised that the general criteria here reported aim to give a general scheme for monitoring networks to be operated in most show caves. In particular situations, when other parameters may become relevant, this one must be taken into account, in addition to those dealt with in the present text.

\section{Main parameters to be considered for monitoring purposes}

In general the following parameters should be recorded:

- Air temperature $\left({ }^{\circ} \mathrm{C}\right)$

- Water temperature $\left({ }^{\circ} \mathrm{C}\right)$ (if applicable)

- Relative humidity (\%)

- $\mathrm{CO}_{2}$ concentration (ppm)

- Radon concentration $\left(\mathrm{Bq} / \mathrm{m}^{3}\right)$

- Other gases (if applicable) 


\section{Temperature}

Temperature can be recorded easily with data loggers or by the employ of suitable sensors in the framework of an automatic monitoring network. The first solution requires a discharge of data from each data logger at given time intervals. Once a month is a frequency currently adopted; the data discharge may be made either connecting the data logger to a computer or though a device called shuttle to avoid problems due to the use of a computer in a cave.

For simple evaluations of the temperature distribution along a cave a precision of at least $0.1^{\circ} \mathrm{C}$ can be accepted; the accuracy of the same order is generally enough because the same instrument generally records the data.

Temperature sensors must be placed possibly at least $1 \mathrm{~m}$ far from walls, formations, etc. and from the soil, taking care to avoid any seepage on them.

A better accuracy may be required for research or other special purpose. A mercury or alcohol thermometers with a resolution of $10^{-2}{ }^{\circ} \mathrm{C}$ may be used for calibration of the electronic devices, e.g. once a year.

\section{Relative humidity}

Humidity sensors can be classified into two categories: the capacitive sensors and the dewpoint probes. The first ones may have a serious problem because, when the relative humidity is close to $100 \%$ (as it is common in caves), they give wrong results on account of the condensation occurring over the sensor. The dewpoint probes are not affected by such an inconvenience but their cost is about one order of magnitude greater than the cost of the capacitive devices.

There are also some humidity sensors (with a cost between the simple capacitive and the dew point) which operate successfully also up to $100 \%$. They need a power supply and the data can be recorded easily in a data logger.

Sometimes a less expensive solution can then be obtained by using an Assmann hygrometer with the thermometers replaced by a multiway differential thermocouple or by a ventilated capacitive sensor. Thus, the sensor would be more easily restored in a dry condition in case of condensation. It is also possible to avoid condensation around $100 \%$, by heating the sensor during the interval between two successive measurements. Heating must be switched out before the measurement early enough to obtain equilibrium with the environment.

For special scientific purposes (e.g. when condensation and evaporation conditions have to be distinguished in the vicinity of $100 \%$ R.H.) evaporimeters only should be used.

These sensors may release some heat and therefore they must be kept far away from temperature sensors to avoid any interference.

\section{$\mathrm{CO}_{2}$ concentration}

This measurement is carried out by infrared absorption by the $\mathrm{CO}_{2}$. Each maker chooses different solutions to avoid interference not due to the $\mathrm{CO}_{2}$ as water vapour. Presently, sensors with measurement ranges for any cave environment are available. Such sensors require too much energy, which cannot be assured by a battery and, therefore, can be installed only where a power supply is available.

Also these sensors may release some heat and therefore they must be kept far away from temperature sensors to avoid any interference. 


\section{Radon concentration}

According to data available up to now there is no evidence of health effects due to radon in caves, nevertheless in many countries the law requires the monitoring of this gas. Therefore it is more convenient to plan such a monitoring which, on the other hand, may also provide some interesting results from a scientific point of view.

Spot measurements are made by means of ionisation chambers or other radiation detectors. Since radon concentration varies greatly it is preferable to obtain average values at least over some hours and, possibly, some days. Instruments with these characteristics are now available. But for long period monitoring other techniques are preferable, as etch track detectors. In this case a plastic film is exposed to radon gas only, by filtering out its decay products, for suitable time (up to some months, if the radon concentration is not too high). Then the films are recovered and the tracks released by the alpha particles are counted. A combination of the two methods is the most convenient: spot measurements to have a rough idea of the radon concentration and the etch tracks to obtain a value averaged over a longer time interval.

\section{Other gases}

In some special case, due to the presence of gases, other than $\mathrm{CO}_{2}$ and radon, in the cave atmosphere, their monitoring may be decided. Obviously each single case must be examined according its local situation and it is not possible to establish a general guideline.

\section{Frequency of measurements}

From the point of view of a normal monitoring, not related to specific local conditions, a frequency ranging from four times per day to once per day, can be adopted. When measurements are taken four times per days, these can be recorded, e.g., at 6:00, 12:00, 18:00 and 24:00.

\section{Time intervals}

On account of the seasonal influence, a preliminary monitoring network should operate for at least one year, possibly two years. Once the climatology of a cave, as well as its visitors capacity are known, it may be decided to continue the operation of the simple preliminary monitoring network or install an automatic monitoring network. This choice depends on the budget of the cave managers and the results expected. 